\title{
Timing of Out-of-hospital Cardiac Arrest and Social Rehabilitation Rate
}

Yuta Sato, Izumi Kuboyama* and Hiroshi Takyu

School of Emergency Medical Systems, Kokushikan University, 7-3-1 Nagayama, Tama-shi, Tokyo, Japan

\section{Abstract}

Timing of out-of-hospital cardiac arrests related to social rehabilitation. To clarify the influence of timing of out-of-hospital cardiac arrests to physical and neurological recovery rates, we conducted a multiple logistic regression analysis through nation wide records of cardiac arrest using Utstein templates. We identified 377,705 cases of witnessed out-of-hospital cardiac arrests. The multiple logistic regression models demonstrated that the odds ratio of timing for nighttime versus daytime was 0.78 (95\% CI $0.76-$ 0.81). We concluded that social rehabilitation following out-of-hospital cardiac arrest during nighttime is poorer than during daytime.

\section{Background}

It is difficult to conduct randomized controlled trials when studying cardiac arrest because of ethical limitations. In order to improve cardiopulmonary resuscitation (CPR) for patients suffering out-of-hospital cardiac arrest (OHCA), interventional studies are critical. Further, well-planned observational studies based on largescale databases potentially reduce the harmful effects of cofounding variables.

All OHCA cases reported by emergency medical personnel are available in the Utstein-templated database in Japan (the Utstein database) since January 2005; this database has become the standard for reporting cardiac arrest incidents since the conference held at the Utstein Abbey in Norway [1]. By using these databases, it is possible to analyze the efficacy of bystander CPR (BCPR) as well as the efficacy of emergency medical services [2]. Successful social rehabilitation without severe neurological or physical impairment after OHCA is one of the primary goals for emergency medical systems, and several studies using the Japanese Utstein database have been reported [3-5].

Though it is naturally important that the emergency medical system must be effective regardless of the time of the incidence, time of day reportedly to affects outcomes in conditions such as stroke [6], ischemic heart disease [7], and pulmonary embolism [8], where outcomes are poorer when patients present at night. A study using the Utstein database from 2005 to 2008 also showed that the prognosis when patients present at night was worse than when they present during the day, and there was no significant difference of prognosis between weekdays and holidays [9]. A similar study evaluating the prognosis of children presenting with emergency medical conditions also found that prognosis was worse at night [10].

In the Utstein database, whether the cardiac arrest was witnessed by a bystander or not is recorded. The prognosis of cardiac arrest is known to depend upon the time span from occurrence of the cardiac arrest to the reception of proper $\mathrm{CPR}$, and evaluating only witnessed cases is required to accurately analyze the dependency of time span on prognosis.

\section{Purpose}

The aim of this study is to elucidate the time dependency of cerebral recovery rates following OHCA using the Utstein database.

\section{Methods}

\section{Study setting}

This study was conducted from January 1, 2005 to December 31, 2012 in Japan, including rural, suburban, and urban areas. The emergency medical services (EMS) comprise basic life support ambulances staffed with paramedics. Ambulances are dispatched at municipal fire defense stations. A telephone operator or a dispatcher receives a request call for an ambulance (at119). EMS is financed by taxes and free access to EMS is guaranteed. Patients with OHCA were electronically recorded in the Utstein template at each fire station and were sent to the Fire Defense and Disaster Agency.

\section{Study population}

The population of Japan is 127 million, $27.3 \%$ of whom are over 65 years, and the number of deaths in 2015 was 1,290,000. About 120,000 cases with OHCA were recorded by EMS, amounting to approximately $10 \%$ of all deaths.

\section{Study design}

Among 925,268 cases of cardiac arrest recorded in the Utstein database from 2005 to 2012, 377,705 cases were selected for analysis using the criterion of being witnessed by a bystander (Figure 1).

We surveyed patient age, gender, the initial electrocardiogram (ECG), a doctor on an ambulance, oral instruction to a bystander by the EMS dispatcher, bystander's cardiopulmonary resuscitation, attempt of defibrillation, airway management, intravenous cannulation, adrenaline administration, year, season, hour of call request, intervals from request call to contact with a patient (call contact interval) and from request call to arrival at a hospital (call hospital interval) and,

"Corresponding Author: Prof. Izumi Kuboyama, School of Emergency Medical Systems, Kokushikan University, 7-3-1 Nagayama, Tama-shi, Tokyo 206-8515, Japan; E-mail: ikuboyam@kokushikan.ac.jp

Citation: Sato y, Kuboyama I, Takyu H (2017) Timing of Out-of-hospital Cardiac Arrest and Social Rehabilitation Rate. Int J Phys Ther Rehab 3: 132. doi: https:// doi.org/10.15344/2455-7498/2017/132

Copyright: @ 2017 Sato et al. This is an open-access article distributed under the terms of the Creative Commons Attribution License, which permits unrestricted use, distribution, and reproduction in any medium, provided the original author and source are credited. 
Page 2 of 4

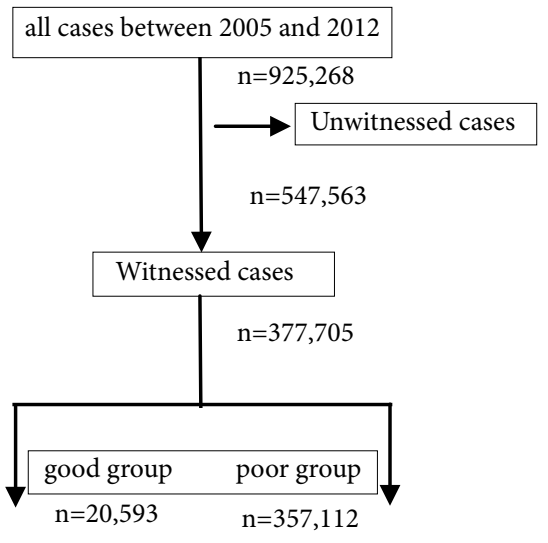

Figure 1. Flow diagram of data selection in the Utstein database.

finally, social rehabilitation. The initial finding of the ECG was divided into the presence of ventricular fibrillation or pulse less ventricular tachycardia (VF/VT) and non-VF/VT. Defibrillated cases were divided into four types: defibrillated only by a bystander (public), only by EMS staff, by both public and EMS, and by no one. BCPR cases were also divided into 4 types: conventional CPR (chest compression and artificial ventilation), chest compression only, artificial ventilation only, and none. The period of cases was divided into 2005-2008 and 2009-2012. Time of request call was divided into daytime (from 09:00 to 16:59) and nighttime (from 17:00 to 08:59). Seasons were defined as spring (from March to May), summer (from June to August), autumn (from September to November), and winter (from December to February).

\section{Outcome}

Our outcome is social rehabilitation, defined as the grade 1 or 2 of Cerebral Performance Category in the Glasgow Pittsburgh Outcome Categories at one month following OHCA. All cases were divided into two groups (Figure 1): a "good" group that has normal or only mild impairment of cerebral performance (category 1 and 2), and a "poor" group that has moderate or severe impairment, brain death, or death (categories 3-5).

\section{Statistical analysis}

We summarized categorical variables using percentages and frequencies, and occurrences of OHCA were depicted in each hour. Chi square tests were used for categorical data between the two groups. We performed a multiple logistic regression analysis to assess the relationship between social rehabilitation and 14 variables. $\mathrm{R}$ (ver. 3.2.0, The R foundation, Austria) was used for statistical analysis.

\section{Ethics}

The Utstein database was analyzed with the permission of the Fire and Disaster Management Agency of the Ministry of Internal Affairs and Communications. This study was approved by the ethical committee of Kokushikan University (no. 27-010).

\section{Results}

We summarized categorical variables using percentages and frequencies among the good and poor groups (Table 1).

Figure 2 shows time dependency of arrest events and successful social rehabilitation. The overall successful rate of social rehabilitation was $5.5 \%(20,593$ cases $/ 377,705)$, and the two lowest rates were $3.9 \%$ between 18:00-18:59 and 4.1\% between 04:00-04:59.

Results of the analysis using a multiple logistic regression are summarized in Table 2. Use of an automatic external defibrillator (AED) showed significantly high odds ratio (OR), especially in cases of public usage $(9.49,95 \%$ confidence interval $8.70-10.34)$. VT/VF also showed high an OR of 1.99 (1.88-2.11) in the initial finding of ECG. The OR of 2009-2012 compared to 2005-2008 was 1.54 (1.49-1.59). The OR decreased with age as that of 85 years old and over was 0.24 (0.22-0.25). The OR of nighttime was 0.78 (0.76-0.81) compared with daytime. The OR of call-contact over 10 minutes was 0.59 (0.58-0.66) compared with 10 minutes and less. The OR of call-hospital interval over 60 minutes was $0.61(0.57-0.66)$ compared with 60 minutes and less.

\section{Discussion}

This nationwide study demonstrates that social rehabilitation following OHCA is worse when the event occurs during the night as

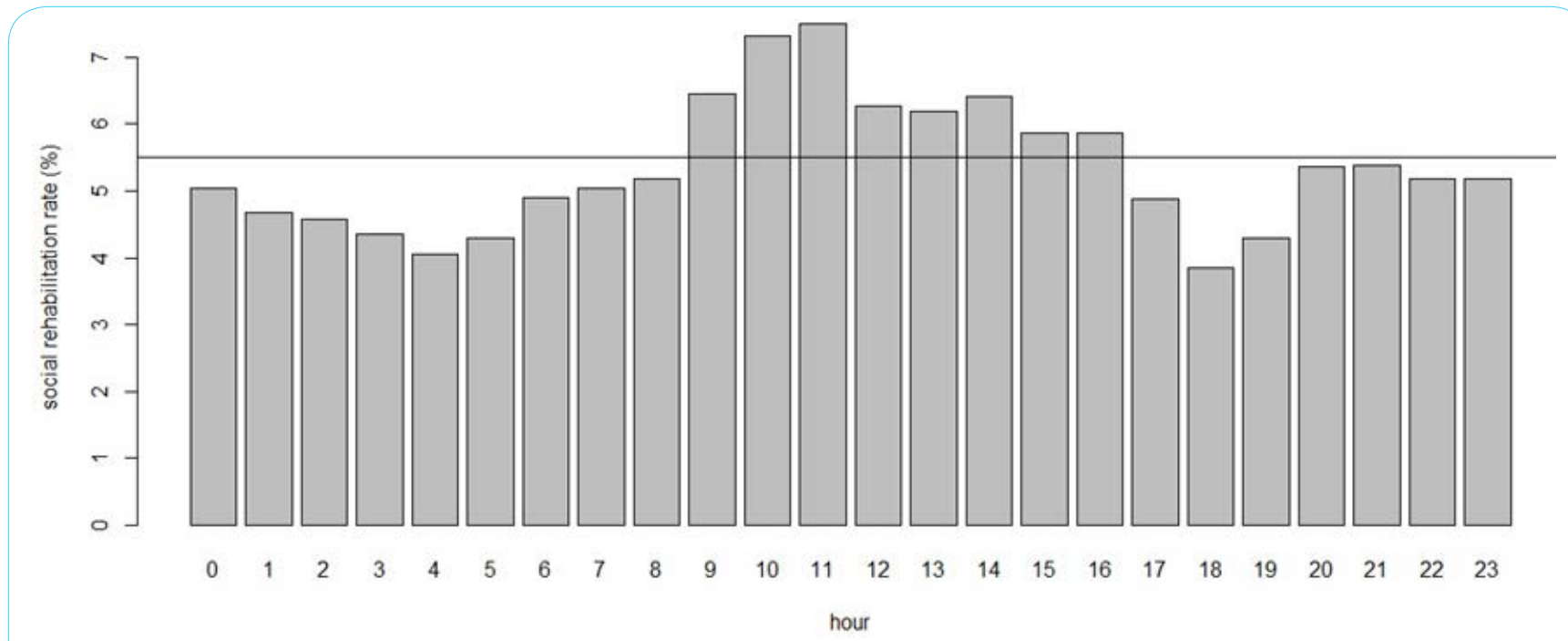

Figure 2: Time of Request call and social rehabilitation rate (\%) in each hour among all cases

The horizontal line is the average (5.5\%). 
Citation: Sato y, Kuboyama I, Takyu H (2017) Timing of Out-of-hospital Cardiac Arrest and Social Rehabilitation Rate. Int J Phys Ther Rehab 3: 132. doi: https:// doi.org/10.15344/2455-7498/2017/132

Page 3 of 4

\begin{tabular}{|c|c|c|c|c|c|c|}
\hline \multicolumn{2}{|c|}{ Variable } & \multicolumn{2}{|c|}{$\begin{array}{l}\text { good group } \\
(\mathrm{n}=20,593)\end{array}$} & \multicolumn{2}{|c|}{$\begin{array}{l}\text { poor group } \\
(\mathrm{n}=357,112)\end{array}$} & \multirow{3}{*}{$\begin{array}{c}\text { probability } \\
<0.01\end{array}$} \\
\hline & & \multirow{2}{*}{$\begin{array}{c}\mathrm{n} \\
14,617 \\
\end{array}$} & \multirow{2}{*}{$\begin{array}{c}\% \\
(71.0) \\
\end{array}$} & \multirow{2}{*}{$\begin{array}{c}\mathrm{n} \\
214,206 \\
\end{array}$} & \multirow{2}{*}{$\begin{array}{c}\% \% \\
(60.0) \\
\end{array}$} & \\
\hline $\operatorname{sex}$ & male & & & & & \\
\hline & female & 5,976 & $(29.0)$ & 142,906 & $(40.0)$ & \\
\hline \multirow[t]{5}{*}{ age } & $\begin{array}{l}0-39 \text { years } \\
\text { old }\end{array}$ & 2,231 & $(10.8)$ & 19,116 & $(5.4)$ & $<0.01$ \\
\hline & $40-64$ & 7,625 & $(37.0)$ & 67,638 & $(18.9)$ & \\
\hline & $65-74$ & 4,602 & $(22.3)$ & 67,655 & $(18.9)$ & \\
\hline & $75-84$ & 4010 & $(19.5)$ & 106,800 & $(29.9)$ & \\
\hline & $85-$ & 2,125 & $(10.3)$ & 95,903 & $(26.9)$ & \\
\hline \multirow[t]{2}{*}{ year } & $2005-2008$ & 8,278 & $(40.2)$ & 165,480 & $(46.3)$ & $<0.01$ \\
\hline & $2009-2012$ & 12,315 & $(59.8)$ & 191,632 & $(53.7)$ & \\
\hline hour & 09:00-16:59 & 10,610 & $(51.5)$ & 157,699 & $(44.2)$ & $<0.01$ \\
\hline \multirow[t]{4}{*}{ season } & spring & 4,969 & $(24.1)$ & 88,695 & $(24.8)$ & $<0.01$ \\
\hline & summer & 4,826 & $(23.4)$ & 73,836 & $(20.7)$ & \\
\hline & autumn & 5,142 & $(25.0)$ & 84,499 & $(23.7)$ & \\
\hline & winter & 5,655 & $(27.5)$ & 110,056 & $(30.8)$ & \\
\hline \multicolumn{2}{|c|}{ cardiac disease } & 5,295 & $(25.7)$ & 164,440 & $(46.0)$ & $<0.01$ \\
\hline initial ECG & $\mathrm{VT} / \mathrm{VF}$ & 11,492 & $(55.8)$ & 318,820 & $(89.3)$ & $<0.01$ \\
\hline \multicolumn{2}{|c|}{ oral instruction } & 6,305 & $(30.6)$ & 123,506 & $(34.6)$ & $<0.01$ \\
\hline \multirow[t]{4}{*}{$\mathrm{BCPR}$} & conventional & 3,598 & $(17.5)$ & 43,888 & $(12.3)$ & $<0.01$ \\
\hline & $\begin{array}{l}\text { chest } \\
\text { compression }\end{array}$ & 6,028 & $(29.3)$ & 86,267 & $(24.2)$ & \\
\hline & respiration & 184 & $(0.9)$ & 2,900 & $(0.8)$ & \\
\hline & none & 10,783 & $(52.4)$ & 224,057 & $(62.7)$ & \\
\hline \multirow[t]{4}{*}{ AED } & public & 1,028 & $(5.0)$ & 2,025 & $(0.6)$ & $<0.01$ \\
\hline & EMS & 9,794 & $(47.6)$ & 50,875 & $(14.2)$ & \\
\hline & public \& EMS & 491 & (2.4) & 1,177 & $(0.3)$ & \\
\hline & none & 9,280 & $(45.1)$ & 303,035 & $(84.9)$ & \\
\hline \multicolumn{2}{|c|}{ doctor on an ambulance } & 3,218 & $(15.6)$ & 43,054 & $(12.1)$ & $<0.01$ \\
\hline \multicolumn{2}{|c|}{ call-contact interval $<=10 \mathrm{~min}$} & 19,461 & $(85.2)$ & 266,622 & $(76.9)$ & $<0.01$ \\
\hline \multicolumn{2}{|c|}{ call-hospital interval $<=60 \mathrm{~min}$} & 17,537 & $(94.5)$ & 342,620 & $(95.9)$ & $<0.01$ \\
\hline \multicolumn{2}{|c|}{ intravenous cannulation } & 2,911 & $(14.1)$ & 9,146 & $(2.6)$ & $<0.01$ \\
\hline \multicolumn{2}{|c|}{ adrenalin administration } & 946 & $(4.6)$ & 43,045 & $(12.1)$ & $<0.01$ \\
\hline
\end{tabular}

Table 1: Profiles of good and poor groups of cerebral function following out-ofhospital cardiac arrests.

the multiple logistic regression model showed the odds ratio of timing for nighttime versus daytime was 0.78 (95\% CI 0.76-0.81). Similarly, Koike reported that the OR of the nighttime OHCA versus daytime OHCA was 1.26 (95\%CI1.20-1.32) [9]. Kitamura also reported that the rehabilitation rate of cardiac events of children under 18 years old was significantly lower when occurring at night (17:00-09:00), with the OR of 0.68 (95\% CI0.56-0.82).

Our study also showed that AED use remarkably improves social rehabilitation, especially when a bystander (OR 9.48, 8.70-10.34) used an AED. We suppose that a bystander could perform AED-assisted CPR faster than EMS staff and this can shorten the interval between cardiac arrest and emergency medical care.

In this study, the OR was 0.59 (95\% CI0.57-0.62) when the call contact interval was over 10 minutes, and 0.61 (95\% CI0.57-0.66) when call hospital interval was there was over 60 minutes. Methods

\begin{tabular}{|c|c|c|c|c|c|}
\hline \multicolumn{2}{|c|}{ Variable } & \multirow{2}{*}{$\begin{array}{c}\text { odds } \\
\text { ratio }\end{array}$} & \multirow{2}{*}{$\begin{array}{l}\text { lower } \\
95 \% \text { CI }\end{array}$} & \multirow{2}{*}{$\begin{array}{l}\text { upper } \\
95 \% \text { CI }\end{array}$} & \multirow[t]{2}{*}{ probability } \\
\hline sex & male & & & & \\
\hline & female & 1.00 & 0.97 & 1.40 & 0.88 \\
\hline \multirow[t]{5}{*}{ age } & $0-39$ years & 1 & & & \\
\hline & $40-64$ & 0.77 & 0.73 & 0.81 & $<0.01$ \\
\hline & $65-74$ & 0.55 & 0.52 & 0.58 & $<0.01$ \\
\hline & $75-84$ & 0.37 & 0.35 & 0.39 & $<0.01$ \\
\hline & $>=85$ & 0.24 & 0.22 & 0.25 & $<0.01$ \\
\hline \multirow[t]{2}{*}{ year } & 2005-2008 & 1 & & & \\
\hline & 2009-2012 & 1.54 & 1.49 & 1.59 & $<0.01$ \\
\hline \multirow[t]{2}{*}{ day \& night } & day time & 1 & & & \\
\hline & night time & 0.78 & 0.76 & 0.81 & $<0.01$ \\
\hline \multirow[t]{4}{*}{ season } & spring & 1 & & & \\
\hline & summer & 1.12 & 1.07 & 1.17 & $<0.01$ \\
\hline & autumn & 1.09 & 1.04 & 1.13 & $<0.01$ \\
\hline & winter & 0.98 & 0.94 & 1.02 & $<0.01$ \\
\hline \multirow[t]{2}{*}{ disease } & cardiac & 1 & & & \\
\hline & non-cardiac & 0.65 & 0.63 & 0.68 & $<0.01$ \\
\hline \multirow[t]{2}{*}{ initial ECG } & non-VT/VF & 1 & & & \\
\hline & VT/VF & 1.99 & 1.89 & 2.11 & $<0.01$ \\
\hline \multirow[t]{4}{*}{ BCPR } & conventional & 1 & & & \\
\hline & $\begin{array}{l}\text { chest } \\
\text { compression }\end{array}$ & 0.91 & 0.87 & 0.96 & $<0.01$ \\
\hline & respiration & 0.90 & 0.76 & 1.05 & 0.19 \\
\hline & none & 0.71 & 0.68 & 0.75 & $<0.01$ \\
\hline \multirow[t]{4}{*}{ AED } & none & 1 & & & \\
\hline & by public & 9.49 & 8.70 & 10.34 & $<0.01$ \\
\hline & by EMS & 2.80 & 2.65 & 2.96 & $<0.01$ \\
\hline & $\begin{array}{l}\text { by public \& } \\
\text { EMS }\end{array}$ & 4.59 & 4.01 & 5.13 & $<0.01$ \\
\hline \multirow{2}{*}{$\begin{array}{l}\text { adrenalin } \\
\text { administration }\end{array}$} & no & 1 & & & \\
\hline & yes & 0.41 & 0.38 & 0.45 & $<0.01$ \\
\hline \multirow{2}{*}{$\begin{array}{l}\text { doctor on an } \\
\text { ambulance }\end{array}$} & no & 1 & & & \\
\hline & yes & 1.06 & 1.02 & 1.11 & $<0.01$ \\
\hline \multirow{2}{*}{$\begin{array}{l}\text { call-contact } \\
\text { interval }\end{array}$} & $\leq 10 \mathrm{~min}$ & 1 & & & \\
\hline & $>10 \mathrm{~min}$ & 0.59 & 0.57 & 0.62 & $<0.01$ \\
\hline \multirow{2}{*}{$\begin{array}{l}\text { call-hospital } \\
\text { interval }\end{array}$} & $\leq 60 \mathrm{~min}$ & 1 & & & \\
\hline & $>60 \mathrm{~min}$ & 0.61 & 0.57 & 0.66 & $<0.01$ \\
\hline \multirow{2}{*}{$\begin{array}{l}\text { intravenous } \\
\text { cannulation }\end{array}$} & no & 1 & & & \\
\hline & yes & 0.51 & 0.49 & 0.54 & $<0.01$ \\
\hline
\end{tabular}

Table 2: Results of multiple regression model.

of shortening the intervals from the initial request call to the first contact with an OHCA patient and arrival at a medical facility would contribute to improvement of social rehabilitation rate.

This study is limited by its observational nature. Further, the Utstein database does not contain diagnosis and the severity of a disease, which influences the prognosis of patients with OHCA. Lastly, we do not assess socioeconomic status such as education, income, and general accessibility to medical services, which has been previously reported as pertinent to this kind of analysis [11]. 
Citation: Sato y, Kuboyama I, Takyu H (2017) Timing of Out-of-hospital Cardiac Arrest and Social Rehabilitation Rate. Int J Phys Ther Rehab 3: 132. doi: https:// doi.org/10.15344/2455-7498/2017/132

\section{Conclusion}

In conclusion, we found that social rehabilitation following OHCA is worse when the event occurs during the night, additionally AED use remarkably improves social rehabilitation rate.

\section{Competing Interests}

The authors declare that they have no competing interests.

\section{References}

1. The European Resuscitation Council, American Heart Association, Heart and Stroke Foundation of Canada, and Australian Resuscitation Council (1992) Recommended guidelines for uniform reporting of data from outof-hospital cardiac arrest (new abridged version). The "Utstein style". Br Heart J 67: 325-333.

2. Franek O, Pokorna M, Sukupova P (2010) Pre-hospital cardiac arrest in Prague, Czech Republic-the Utstein-style report. Resuscitation 81: 831 835

3. Kitamura T, Iwami T, Kawamura T et al (2010) Nationwide public-access defibrillation in Japan. N Engl J Med 362: 994-1004.

4. Iwamura T, Sakamoto $\mathrm{Y}$, Kutsukata N, Nakashima A, Yamashita T, et al. (2013) An Utstein-style examination of out-of-hospital cardiac arrest patients in Saga Prefecture, Japan. J Nippon Med Sch 80: 184-191.

5. Kuboyama I, Sato Y, Takyu H (2016) Time-series errors in Utstein data. Kokushikan soc sport scienc 16: 7-12.

6. Saposnik G, Baibergenova A, Bayer N et al (2007) Weekends: a dangerous time for having a stroke? Stroke 38: 1211-1215.

7. Kostis WJ, Demissie K, Marcella SW, Shao YH, Wilson AC, et al. (2007) Weekend versus weekday admission and mortality from myocardia infarction. N EnglJMed 356: 1099-1109.

8. Aujesky D, Jiménez D, Mor MK, Geng M, Fine MJ, et al. (2009) Weekend versus weekday admission and mortality after acute pulmonary embolism. Circulation 119: 96-968

9. Koike S, Tanabe S, Ogawa T, Akahane M, Yasunaga H, et al. (2011) Effect of time and day of admission on1-month survival and neurologically favourable 1-month survival in out-of-hospital cardiopulmonary arrest patients. Resuscitation 82: 863-868

10. Kitamura T, Kiyohara K, Nitta M, Nadkarni VM, Berg RA, et al. (2014) Survival following witnessed pediatric out-of-hospital cardiac arrests during nights and weekends. Resuscitation 85: 1692-1698.

11. Kragholm $\mathrm{K}$, Wissenberg $\mathrm{M}$, Mortensen RN, Fonager $\mathrm{K}$, Jensen SE et al. (2015) Return to work in out-of-hospital cardiac arrest survivors a nationwide register-based follow-up study. Circulation 131: 1682-1690. 